Kevin S. Hughes and Barbara L. Smith, Massachusetts General Hospital; Jennifer R. Bellon and Eric P. Winer, DanaFarber Cancer Institute, Boston, MA; Lauren A. Schnaper, Greater Baltimore Medical Center, Baltimore, MD; Constance T. Cirrincione, Alliance/Cancer and Leukemia Group B Statistics and Data Center, Duke University, Durham; Hyman B. Muss, University of North Carolina Lineberger Comprehensive Cancer Center, Chapel Hill, NC; Donald A. Berry, University of Texas MD Anderson Cancer Center, Houston, TX; Beryl McCormick and Clifford A. Hudis, Memorial Sloan-Kettering Cance Center, New York, NY; and William C. Wood, Emory University School of Medicine, Atlanta, GA.

Published online ahead of print at www.jco.org on May 20, 2013.

Written on behalf of the Cancer and Leukemia Group B, Radiation Therapy Oncology Group, and Eastern Cooperative Oncology Group.

Authors' disclosures of potential conflicts of interest and author contributions are found at the end of this article.

Corresponding author: Kevin S. Hughes, MD, FACS, Surgical Director, Breast Screening, Co-Director, Avon Comprehensive Breast Evaluation Center, Massachusetts General Hospital, Associate Professor of Surgery, Harvard Medical School, 55 Fruit St, Yawkey 7, Boston, MA 02114; e-mail: kshughes@ partners.org

(C) 2013 by American Society of Clinica Oncology

0732-183X/13/3119w-2382w/\$20.00

DOI: $10.1200 / J C O .2012 .45 .2615$

\title{
Lumpectomy Plus Tamoxifen With or Without Irradiation in Women Age 70 Years or Older With Early Breast Cancer: Long-Term Follow-Up of CALGB 9343
}

Kevin S. Hughes, Lauren A. Schnaper, Jennifer R. Bellon, Constance T. Cirrincione, Donald A. Berry, Beryl McCormick, Hyman B. Muss, Barbara L. Smith, Clifford A. Hudis, Eric P. Winer, and William C. Wood

See accompanying editorial on page 2367 and article on page 2377

$$
\text { A } \begin{array}{llllllll}
\text { B } & \text { S } & \text { T } & \text { R } & \text { A } & \text { C } & \text { T }
\end{array}
$$

\section{Purpose}

To determine whether there is a benefit to adjuvant radiation therapy after breast-conserving surgery and tamoxifen in women age $\geq 70$ years with early-stage breast cancer.

\section{Patients and Methods}

Between July 1994 and February 1999, 636 women (age $\geq 70$ years) who had clinical stage I (T1N0M0 according to TNM classification) estrogen receptor (ER) -positive breast carcinoma treated by lumpectomy were randomly assigned to receive tamoxifen plus radiation therapy (TamRT; 317 women) or tamoxifen alone (Tam; 319 women). Primary end points were time to local or regional recurrence, frequency of mastectomy, breast cancer-specific survival, time to distant metastasis, and overall survival (OS).

\section{Results}

Median follow-up for treated patients is now 12.6 years. At 10 years, 98\% of patients receiving TamRT (95\% Cl, 96\% to 99\%) compared with $90 \%$ of those receiving Tam $(95 \% \mathrm{Cl}, 85 \%$ to $93 \%$ ) were free from local and regional recurrences. There were no significant differences in time to mastectomy, time to distant metastasis, breast cancer-specific survival, or OS between the two groups. Ten-year OS was $67 \%(95 \% \mathrm{Cl}, 62 \%$ to $72 \%)$ and $66 \%(95 \% \mathrm{Cl}, 61 \%$ to $71 \%)$ in the TamRT and Tam groups, respectively.

\section{Conclusion}

With long-term follow-up, the previously observed small improvement in locoregional recurrence with the addition of radiation therapy remains. However, this does not translate into an advantage in OS, distant disease-free survival, or breast preservation. Depending on the value placed on local recurrence, Tam remains a reasonable option for women age $\geq 70$ years with ER-positive early-stage breast cancer.

\section{J Clin Oncol 31:2382-2387. (C) 2013 by American Society of Clinical Oncology}

\section{INTRODUCTION}

Radiation therapy (RT) after breast-conserving surgery decreases the risk of ipsilateral breast recurrence (IBTR). Several studies have suggested that there exists a favorable subgroup of patients in whom irradiation may not provide meaningful overall benefit, including but not limited to older women with smaller estrogen receptor (ER) -positive cancers treated with antihormonal therapy. ${ }^{1-5}$ To test this hypothesis, the Cancer and Leukemia Group B (CALGB) initiated CALGB 9343, a randomized trial comparing the efficacy of tamoxifen alone (Tam) with tamoxifen plus RT (TamRT) in older women with ER-positive, clinical stage I breast cancer.

When reported in 2004 (median follow-up, 5 years), ${ }^{6}$ the 5 -year incidence of IBTR or regional nodal recurrence was $4 \%$ for patients receiving Tam and $1 \%$ for those receiving TamRT. There was no difference in survival, time to distant metastasis, or ultimate breast-preservation rate. Examining Medicare data through 2007, Soulis et $\mathrm{al}^{7}$ found that our report had little impact, with the use of irradiation only slightly diminishing in this population. Because it was possible that with longer-term follow-up our results might not persist, we performed this longterm analysis to address these concerns.

\section{PATIENTS AND METHODS}

The methods of this study have been previously described. ${ }^{6}$ CALGB 9343 was designed in cooperation with the Eastern Cooperative Oncology Group (ECOG) and 
Radiation Therapy Oncology Group (RTOG). Local institutional review boards reviewed and approved the study in compliance with the Declaration of Helsinki. Written informed consent was obtained from all patients. An independent data and safety monitoring committee provided oversight. The CALGB Statistical Center managed data collection, and data quality was ensured by the study chairperson and statistical center review. CALGB statisticians performed the statistical analyses. The CALGB quality-assurance program has been previously described. ${ }^{6}$

\section{Patient Selection}

Women age $\geq 70$ years with clinical stage I, ER-positive breast cancer and no history of cancer other than in situ cervical or nonmelanoma skin cancer within 5 years were eligible. Initial eligibility criteria included breast cancers up to $4 \mathrm{~cm}$ regardless of estrogen receptor status, but this was reduced in August 1996 to $\leq 2 \mathrm{~cm}$ (T1) with ER-positive or indeterminate receptor status. Patients were required to have clinically negative axillae.

\section{Treatment}

At entry, patients were randomly assigned (1:1 ratio) to receive Tam or TamRT. ${ }^{6}$ Random assignment was stratified by age ( $<75 v \geq 75$ years) and axillary dissection (yes $v$ no). Patients were observed every 4 months for 5 years and yearly thereafter. This study did not rigorously capture tamoxifen discontinuation.

Local therapy. All women underwent lumpectomy with a clear margin (absence of tumor at the inked margin). Axillary node dissection was allowed but not encouraged. RT included tangential fields to the entire breast followed by an electron boost to the lumpectomy site. ${ }^{6}$

Tamoxifen. All women received $20 \mathrm{mg}$ of tamoxifen per day for 5 years, initiated either during or after irradiation. Adjuvant hormonal treatment beyond 5 years was discretionary.

\section{Study End Points}

The primary study end points were time to locoregional recurrence, frequency of mastectomy for recurrence, breast cancer-specific survival, time to distant metastasis, and overall survival (OS). IBTR was defined as any cancer in the ipsilateral breast. Regional recurrence was defined as any recurrence in the ipsilateral supraclavicular, infraclavicular, or axillary nodes. Secondary end points were cosmetic results, as judged by physician and patient, and adverse effects such as breast pain and skin changes.

\section{Actuarial Survival}

The expected proportion of women in this study who would be alive at each year after random assignment was found assuming the women were randomly sampled from women of the same age in the general population. We used the 2001 period life table of the US Social Security Administration (approximate middle of follow-up for this study). We compared actual survival proportion and its confidence limits over time after random assignment of women in the study with their actuarial survival distribution.

\section{Statistical Analysis}

This study was designed with $90 \%$ power to detect a (one-sided) difference in 3-year locoregional recurrence between Tam at $16 \%$ versus TamRT at $9 \%$. The target sample size was 572 patients; however, we overaccrued the study to 647 to compensate for the smaller than expected number of observed events.

The primary comparison of treatment arm on time-to-event end points used proportional hazards modeling adjusted for tumor size, patient age, and axillary dissection. Hazard ratios (HRs), constructed as TamRT to Tam, and their 95\% CIs were taken from these multivariate models. Distributions of time-to-event variables were estimated according to the Kaplan-Meier method, ${ }^{8}$ and distributions were compared between treatment groups by means of the log-rank test. ${ }^{9}$ All $P$ values are two sided and unadjusted for multiplicity. In terms of survival, the study was not powered to prove noninferiority.

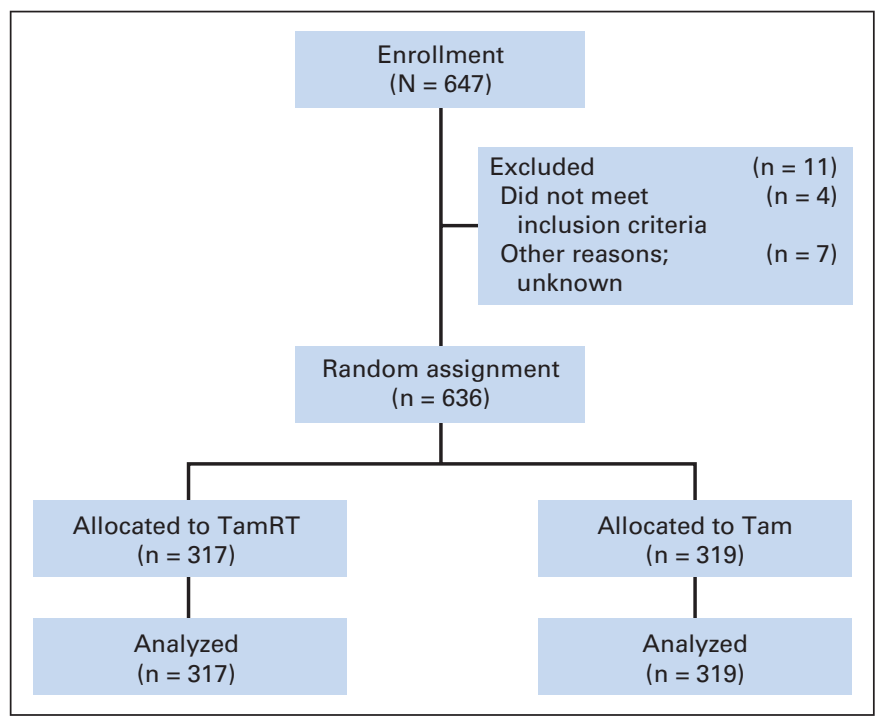

Fig 1. CONSORT diagram. Tam, tamoxifen alone; TamRT, tamoxifen plus radiation therapy.

\section{RESULTS}

The study was initiated by the CALGB (July 1994) and by the RTOG and ECOG (December 1996). Enrollment ended in February 1999 with 647 women: CALGB, 307; ECOG, 112; and RTOG, 228 (Fig 1). Eleven patients (2\%) never began protocol treatment. Statistical analyses used a modified intent-to-treat approach that included all 636 patients who began protocol treatment: 317 with TamRT and 319 with Tam. Before the eligibility change, 10 patients with ER-negative tumors and 13 patients with tumors $>2 \mathrm{~cm}$ were entered. Baseline characteristics of the women were similar in the two groups (Appendix Table A1, online only).

As of January 2011, median follow-up was 12.6 years (maximum, 16.5 years). Of the 636 treated patients, 335 (53\%) survived at least 10 years, 227 of whom remain in active follow-up. Because the observed treatment effect was similar when assessed by both log-rank and multivariate methods, we quote the $P$ values from only the log-rank test.

\section{Time to Locoregional Recurrence}

As compared with the Tam group, the TamRT group experienced a significantly longer time to locoregional recurrence (observed HR, 0.18 ; $95 \%$ CI, 0.07 to $0.42 ; P<.001$; Fig 2 ). At 10 years, $90 \%$ of patients in the Tam group ( $95 \%$ CI, $85 \%$ to $93 \%$ ) compared with $98 \%$ in the TamRT group (95\% CI, 96\% to 99\%) were free from locoregional recurrence. Thirty-two women in the Tam group experienced locoregional recurrence; of these, 20 had only IBTR; six, IBTR with distant metastasis; five, only axillary recurrence; and one, both IBTR and axillary recurrence. Six women in the TamRT group experienced locoregional recurrence; all six were IBTRs (Table 1). At 10 years, 91\% in the Tam group (95\% CI, 87\% to $94 \%$ ) compared with $98 \%$ in the TamRT group (95\% CI, $96 \%$ to $99 \%$ ) were free from local (IBTR) recurrence.

There were no axillary recurrences among the 244 women who underwent initial axillary dissection. Among those who did not undergo axillary dissection, there were no axillary recurrences in the TamRT group; there were six of 200 in the Tam group. 


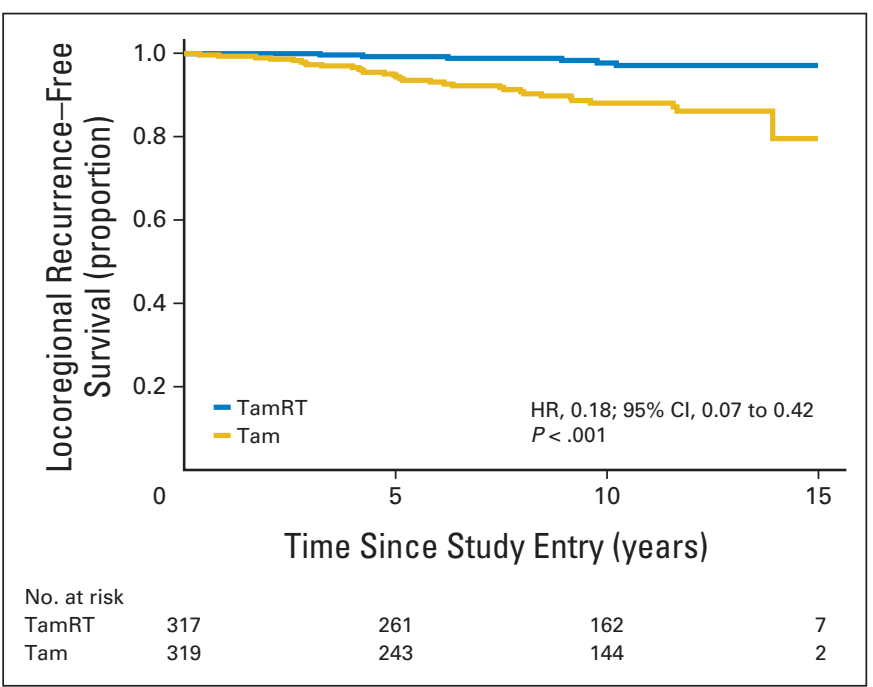

Fig 2. Time to local or regional recurrence. HR, hazard ratio; Tam, tamoxifen alone; TamRT, tamoxifen plus radiation therapy.

\section{Treatment of IBTR}

Six patients receiving TamRT and 27 receiving Tam had in-breast recurrences (IBTRs). Of these, four (TamRT) and 10 (Tam) underwent mastectomy. One patient in the TamRT arm underwent lumpectomy without RT; 13 in the Tam arm underwent lumpectomy (four without RT, eight with RT, and one unknown RT).

\section{Time to Mastectomy}

Time to mastectomy did not differ significantly between the two treatment groups (observed HR, 0.50; 95\% CI, 0.17 to 1.48 ; $P=.17$; Fig 3). The 10-year probability of not undergoing mastectomy was $98 \%$ (95\% CI, 96\% to 99\%) in the TamRT group and 96\% (95\% CI, $93 \%$ to $98 \%$ ) in the Tam group.

\section{Time to Distant Metastasis}

Time to distant metastasis did not differ significantly between the two treatment groups $(P=.50$; Fig 4$)$; distant relapse occurred in 21 patients in the TamRT group ( 13 have died as a result of breast cancer) and 16 in the Tam group (eight have died as a result of breast cancer). The 10-year probability of freedom from distant metastasis was 95\%

\begin{tabular}{|c|c|c|c|}
\hline Treated Patients & TamRT Arm & Tam Arm & Total \\
\hline Total & 317 & 319 & 636 \\
\hline Recurrence & 23 & 42 & 65 \\
\hline Local or regional \pm distant & 6 & 32 & 38 \\
\hline IBTR alone & 2 & 20 & 22 \\
\hline Axilla alone & 0 & 5 & 5 \\
\hline IBTR with axilla & 0 & 1 & 1 \\
\hline IBTR with distant & 4 & 6 & 10 \\
\hline Distant alone & 17 & 10 & 27 \\
\hline \multicolumn{4}{|l|}{ Death } \\
\hline All cause & 166 & 168 & 334 \\
\hline Breast cancer specific & 13 & 8 & 21 \\
\hline $\begin{array}{l}\text { Abbreviations: IBTR, ipsilate } \\
\text { TamRT, tamoxifen plus radiation }\end{array}$ & $\begin{array}{l}\text { east recurren } \\
y \text {. }\end{array}$ & Tam, tamo & alone; \\
\hline
\end{tabular}

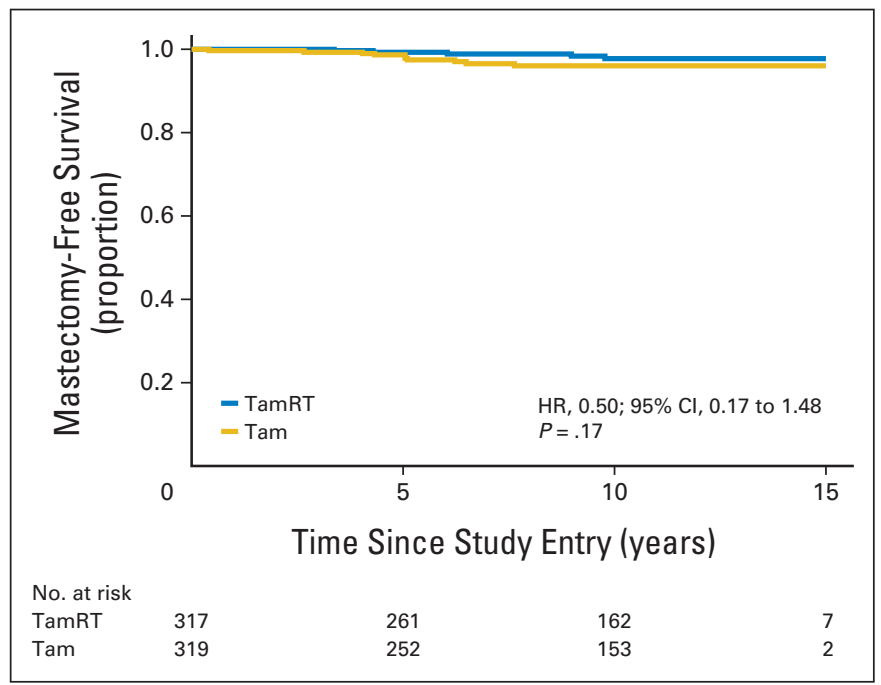

Fig 3. Time to subsequent mastectomy. HR, hazard ratio; Tam, tamoxifen alone; TamRT, tamoxifen plus radiation therapy.

(95\% CI, $92 \%$ to $97 \%$ ) in the TamRT group and $95 \%$ (95\% CI, $91 \%$ to $97 \%$ ) in the Tam group (observed HR, $1.20 ; 95 \% \mathrm{CI}, 0.63$ to 2.32 ).

\section{Survival}

Of the 636 women in the trial, there were 334 deaths: 166 in the TamRT arm and 168 in the Tam arm (HR, 0.95; 95\% CI, 0.77 to 1.18). The respective 10 -year estimates of OS were $67 \%$ (95\% CI, $62 \%$ to $72 \%$ ) and $66 \%$ (95\% CI, 61\% to 71\%; Fig 5). Only 21 of the deaths $(6.3 \%)$ resulted from breast cancer: 13 in the TamRT arm and eight in the Tam arm (HR, 1.55; 95\% CI, 0.64 to 3.74). The respective 10 -year breast cancer-specific survival estimates (Appendix Fig A1, online only) were $97 \%$ (95\% CI, 94\% to $99 \%$ ) and $98 \%$ (95\% CI, 95\% to $99 \%$ ). Figure 6 shows survival proportion over time for women in this study (both groups combined) in comparison with the expected survival proportion of age-matched women in the general population.

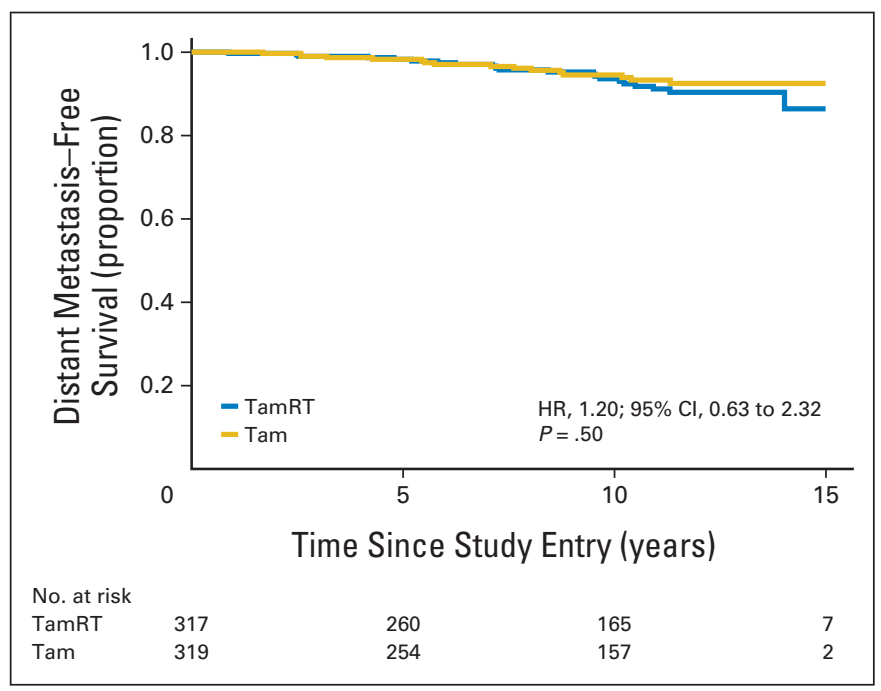

Fig 4. Time to distant metastasis. HR, hazard ratio; Tam, tamoxifen alone; TamRT, tamoxifen plus radiation therapy. 


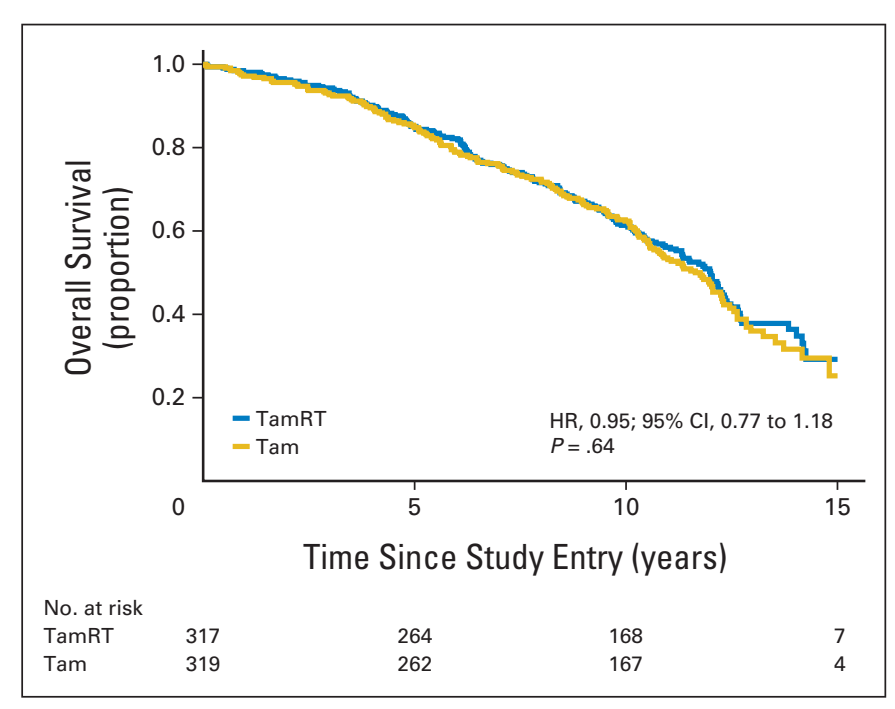

Fig 5. Overall survival. HR, hazard ratio; Tam, tamoxifen alone; TamRT, tamoxifen plus radiation therapy.

\section{Noninferiority}

The study lacks the power to prove that the trend toward greater survival (HR, 0.95) and time to mastectomy (HR, 0.50) in the TamRT group or the trend toward greater breast cancer-specific survival (HR, 1.55) and freedom from distant metastasis (HR, 1.20) in the Tam arm would not continue.

\section{DISCUSSION}

At a median follow-up of 12.6 years, we demonstrate that at 10 years, the incidence of locoregoreginal recurrence is $8 \%$ lower, and the incidence of IBTR is 7\% lower, with TamRT versus Tam alone. This difference is statistically significant. The addition of RT seems to provide no benefit in terms of OS, distant disease-free survival, or ultimate breast preservation, with the proviso that the study lacked the power to definitively show noninferiority of either arm. Importantly, the study also shows that the impact of breast cancer in this select group of older women is much smaller than that of comorbid conditions. Of the 636 women in this study, only $21(3 \%)$ have died as a result of breast

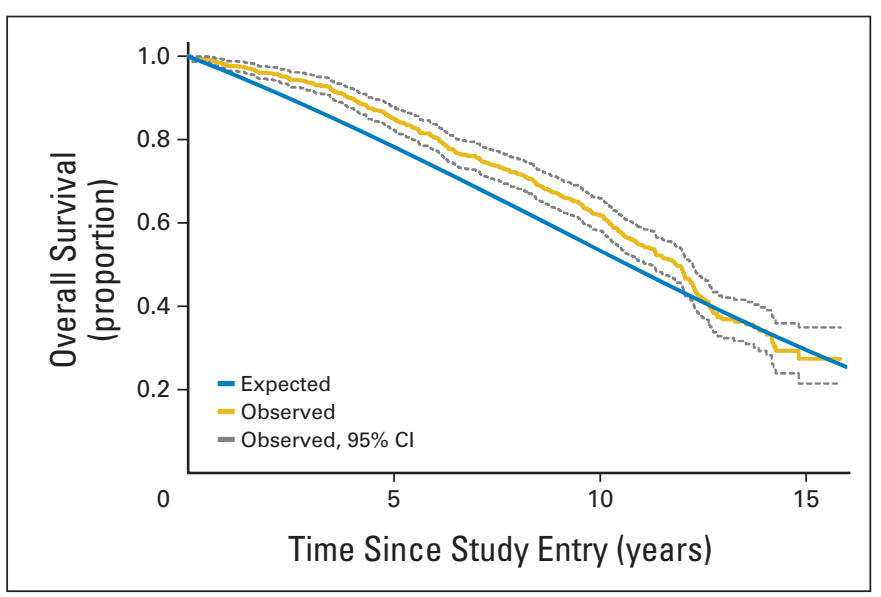

Fig 6. Observed versus expected survival. cancer, whereas $313(49 \%)$ have died as a result of other causes (only $6 \%$ of deaths attributed to breast cancer).

As breast conservation became an accepted approach in the 1980s, it was thought that there were subgroups of women in whom RT might be safely eliminated. Several randomized trials were initiated that compared the efficacy of Tam versus TamRT after lumpectomy (Appendix Table A2, online only). All were based on the premise that women at low risk of recurrence might benefit from less treatment. Trials used varying combinations of postulated low-risk factors, such as older age, smaller tumors, and tumors with favorable prognostic factors. Although all of the trials examined the question of eliminating RT, CALGB 9343 differed from other trials in the factors chosen for eligibility. The National Surgical Adjuvant Breast and Bowel Project (NSABP) B21 trial ${ }^{1}$ was based on tumor size of $\leq 1 \mathrm{~cm}$, included younger women, and had three arms: Tam, TamRT, and RT placebo. The Austrian Breast and Colorectal Cancer Study Group trial ${ }^{4}$ had a mean age of 66 years, tumor size $<3 \mathrm{~cm}$, and hormone treatment with either tamoxifen or anastrazole. The German Breast Cancer Group trial $(\mathrm{GBCG}-\mathrm{V})^{5}$ allowed women as young as age 45 years and used a $2 \times 2$ factorial design (RT or no RT; Tam or no Tam). The British Association of Surgical Oncology (BASO) BASO II trial ${ }^{2}$ followed a similar $2 \times 2$ factorial design. Tinterri et al $^{10}$ randomly assigned women between the ages of 55 and 75 years to either RT and no RT but allowed systemic therapy as dictated by tumor characteristics. Despite the differences in design, no study showed significant differences in distant disease-free survival or OS, although all showed some decrease in IBTR with RT. The differences in terms of eligibility criteria likely account for the differences seen in the effect of RT on breast recurrence.

CALGB 9343 was originally conceived based on several observations. First, adjuvant RT after breast-conserving surgery does not change survival. The Early Breast Cancer Trialists' Collaborative Group 2005 meta-analysis ${ }^{11}$ reported a significant reduction in mortality at 15 years with RT, but it is clear that this only applied if the difference in IBTR was $>10 \%$. Most trials reported here revealed a difference in IBTR of $<10 \%$. The data continue to support no survival advantage with the addition of adjuvant RT in the cohorts represented by these trials.

Second, older women have fewer local recurrences. The Milan III trial $^{12}$ suggested that with quadrantectomy and axillary dissection alone, the rate of IBTR decreased with advancing age. Women age $<45$ years had a $17.5 \%$ rate of IBTR, whereas those age $>55$ years had a $3.8 \%$ rate of IBTR. The trials listed in Appendix Table A2 (online only) reinforce this finding, demonstrating a trend toward higher IBTR in younger women with or without RT.

Third, adjuvant Tam after breast conservation decreases the risk of in-breast recurrence. ${ }^{13}$ Older women tend to have estrogensensitive tumors, ${ }^{14}$ and tamoxifen efficacy increases directly with levels of estrogen receptor expression. ${ }^{15}$ Tumor estrogen and progesterone receptor levels increase over time with maximum expression in women age $>75$ years. ${ }^{16}$ Moreover, when compared with Tam, aromatase inhibitors (AIs) seem to show an even further decrease in risk of IBTR. ${ }^{17}$ In a meta-analysis of randomized trials comparing 5 years of either adjuvant Tam or an AI, patients receiving an AI had an HR of 0.70 for isolated local recurrence as a first event (two-sided $P=.03$ ).

Fourth, local recurrence after breast-conserving treatment without irradiation can be salvaged by repeat lumpectomy or lumpectomy 
with RT. Preservation of the breast, even after IBTR, has been demonstrated by Liligren et al, ${ }^{18}$ Clark et al, ${ }^{19}$ and Veronesi et al. ${ }^{12}$ In our study, there was no significant difference in ultimate rate of breast preservation.

We note that the definition of negative margins has changed since this study began. CALGB 9343 accepted the NSABP standard of no ink on tumor, essentially a one-cell minimum margin. Today, the trend is toward greater negative margins, usually 1 to $2 \mathrm{~mm},{ }^{20,21}$ and the low rate of IBTR without RT in this study might further decrease with wider excision, suggesting that any benefit of RT over antiestrogen treatment alone in local recurrence may be of even less significance today.

In our study, treatment of the axilla was left to the discretion of the physician. Among women who did not have an axillary dissection upfront, none in the TamRT arm experienced recurrence in the axilla; however, six (3\%) in the Tam arm did. In the absence of RT or sentinel node biopsy, we might expect a 3\% increase in local control compared with RT or sentinel node biopsy. If the results of a sentinel node biopsy are not likely to change the choice of systemic treatment, it is questionable whether this 3\% decrement warrants the use of sentinel node biopsy in this population.

Fifth, shorter life expectancy in older women leaves less time for local recurrence. We anticipated that many women would die as a result of competing causes in a relatively short period of time and thus not live long enough to be at risk for IBTR. This was not correct, because the median survival was 12 years, and yet the rate of IBTR remained low. We would suggest that in this older population, comorbid conditions, not specific breast cancer treatments, dictate survival, and the biology of the tumor dictates the rate of IBTR, not the length of life.

Time to distant metastasis did not differ between the two treatment groups and continues to be low. The 10-year incidence of distant disease was only $5 \%$ in the Tam RT group and 5\% with Tam alone.

The women in this study were significantly healthier and lived considerably longer than the general population of that set of ages. This suggests that the results of this study apply to healthy women in this age group, not just to those with comorbidities.

The durability of the results of this study is encouraging. When first presented, there was concern that with longer follow-up, the number of recurrences would increase. However, the number of events for both groups remains low. With median follow-up of 12.6 years, 334 of 636 women have died, but only 21 (6\%) of these have died as a result of breast cancer. In comparison with our previous report of these results at median follow-up of 5 years, ${ }^{6}$ as expected, the all-cause mortality proportion has increased, but it is still similar between the two arms. The 10-year incidence of breast cancer survival is low in both arms.

The toxicity of tamoxifen is not trivial, particularly in this elderly population. Well-known adverse effects include hot flashes, thrombotic events, and a small risk of endometrial cancer. ${ }^{22}$ However, despite the possibility that all patients were not able to complete the prescribed course of treatment, local control, distant disease-free survival, and cancer-specific survival remained excellent in this population with generally favorable disease characteristics.

Despite the observed similarity in OS and absolute risk reduction by breast irradiation in locoregional recurrence of only $7 \%$, this study has not had a notable impact on clinical practice. The recent article by Soulos et $\mathrm{al}^{7}$ found that RT use decreased $<5 \%$ after publication and dissemination of the data. The decision to use RT may depend more on concerns about our initial short-term 5-year follow-up, patient perception of substandard treatment, choosing the length of time for RT versus tamoxifen, financial considerations, and physician equipoise. The editorial by Giordano ${ }^{23}$ accompanying that article suggested that given the same level of significance, physicians are more likely to adopt a change in practice that adds or enhances a treatment, rather than a change in which a treatment is withdrawn.

CALGB 9343 was conceived based on the hypothesis that there was a subset of patients in NSABP B06 who did not benefit from breast irradiation after lumpectomy. We observed the indolent behavior of breast cancer in older women in everyday clinical practice and used that as the basis for our study design. Our goal was to offer this cohort of women another treatment option that might decrease morbidity, allow for adaption to social issues, and not complicate other medical problems. Our study offers evidence that such women should have the option of breast-conserving therapy even without RT.

Long-term follow-up of CALGB 9343 confirms and extends the earlier report that in women age $\geq 70$ years with clinical stage I, ER-positive breast cancer treated with lumpectomy followed by tamoxifen, irradiation adds no significant benefit in terms of survival, time to distant metastasis, or ultimate breast preservation, even though it provides a small decrease in IBTR.

\section{AUTHORS' DISCLOSURES OF POTENTIAL CONFLICTS OF INTEREST}

The author(s) indicated no potential conflicts of interest.

\section{AUTHOR CONTRIBUTIONS}

Conception and design: Kevin S. Hughes, Lauren A. Schnaper, Constance T. Cirrincione, Donald A. Berry, Hyman B. Muss, William C. Wood

Administrative support: Kevin S. Hughes, Constance T. Cirrincione, Beryl McCormick, Hyman B. Muss, Clifford A. Hudis, Eric P. Winer, William C. Wood

Provision of study materials or patients: Kevin S. Hughes, Beryl McCormick, Hyman B. Muss, Barbara L. Smith, Clifford A. Hudis, Eric P. Winer, William C. Wood

Collection and assembly of data: Kevin S. Hughes, Constance T. Cirrincione, Donald A. Berry, Beryl McCormick

Data analysis and interpretation: All authors

Manuscript writing: All authors

Final approval of manuscript: All authors

\section{REFERENCES}

1. Fisher B, Bryant J, Dignam JJ, et al: Tamoxifen, radiation therapy, or both for prevention of ipsilateral breast tumor recurrence after lumpectomy in women with invasive breast cancers of one centimeter or less. J Clin Oncol 20:4141-4149, 2002

2. Blamey RW, Chetty U, Bates $T$, et al: Radiotherapy and/or tamoxifen after conserving surgery for breast cancers of excellent prognosis: BASO II trial. Eur J Cancer 6:55, 2008 (suppl)

3. Fyles AW, McCready DR, Manchul LA, et al: Tamoxifen with or without breast irradiation in women 50 years or older with early breast cancer. N Engl J Med 351:963-970, 2004

4. Pötter R, Gnant M, Kwasny W, et al: Lumpectomy plus tamoxifen or anastrozole with or without whole breast irradiation in women with favorable early breast cancer. Int J Radiat Oncol Biol Phys 68:334-340, 2007 
5. Winzer KJ, Sauerbrei $W$, Braun $M$, et al: Radiation therapy and tamoxifen after breastconserving surgery: Updated results of a $2 \times 2$ randomised clinical trial in patients with low risk of recurrence. Eur J Cancer 46:95-101, 2010

6. Hughes KS, Schnaper LA, Berry D, et al: Lumpectomy plus tamoxifen with or without irradiation in women 70 years of age or older with early breast cancer. N Engl J Med 351:971-977, 2004

7. Soulos PR, Yu JB, Roberts KB, et al: Assessing the impact of a cooperative group trial on breast cancer care in the Medicare population. J Clin Oncol 30:1601-1607, 2012

8. Kaplan EL, Meier P: Nonparametric estimation from incomplete observations. J Am Stat Assoc 53:457-481, 1958

9. Peto R, Pike MC, Armitage $P$, et al: Design and analysis of randomized clinical trials requiring prolonged observation of each patient: II. Analysis and examples. Br J Cancer 35:1-39, 1977

10. Tinterri C, Gatzemeier, Zanini $V$, et al: Conservative surgery with and without radiotherapy in elderly patients with early-stage breast cancer: A prospective randomized multicentre trial. Breast 18 373-377, 2009

11. Clarke M, Collins R, Darby $S$, et al: Effects of radiotherapy and of differences in the extent of surgery for early breast cancer on local recurrence and 15-year survival: An overview of the randomised trials. Lancet 366:2087-2106, 2005

12. Veronesi $U$, Luini $A$, Del Vecchio $M$, et al: Radiotherapy after breast-preserving surgery in women with localized cancer of the breast. N Engl J Med 328:1587-1591, 1993

13. Fisher $B$, Constantino $J$, Redmond $C$, et al: Tamoxifen treatment for breast cancer: A randomized clinical trial evaluating tamoxifen in the treatment of patients with node-negative breast cancer who have estrogen-receptor-positive tumors. N Engl J Med 320:479-484, 1989

14. Wyld L, Reed MW: The need for targeted research into breast cancer in the elderly. Br J Surg 90:388-389, 2003

15. Tamoxifen for early breast cancer: An overview of the randomised trials-Early Breast Cancer Trialists' Collaborative Group. Lancet 351:14511467, 1998

16. Gennari R, Curigliano G, Rotmenz N, et al: Breast carcinoma in elderly women: Features of disease presentation, choice of local and systemic treatments compared with younger postmenopausal patients. Cancer 101:1302-1310, 2004

17. Dowsett M, Cuzick J, Ingle J, et al: Metaanalysis of breast cancer outcomes in adjuvant trials of aromatase inhibitors versus tamoxifen. J Clin Oncol 28:509-518, 2010
18. Liljegren G, Holmberg $L$, Adami $H O$, et al: Sector resection with or without postoperative radiotherapy for stage I breast cancer: Five-year results of a randomized trial-Uppsala-Orebro Breast Cancer Study Group. J Natl Cancer Inst 86:717-722, 1994

19. Clark RM, McCulloch PB, Levine $M N$, et al: Randomized clinical trials to assess the effectiveness of breast irradiation following lumpectomy and axillary dissection for node-negative breast cancer. J Natl Cancer Inst 84:683-689, 1992

20. Azu M, Abrahamse P, Katz SJ, et al: What is an adequate margin for breast-conserving surgery? Surgeon attitudes and correlates. Ann Surg Oncol 17:558-563, 2010

21. Kaufmann M, Morrow M, Von Minckwitz G, et al: Locoregional treatment of primary breast cancer: Consensus recommendations from an international expert panel. Cancer 116:184-191, 2010

22. Amir E, Seruga B, Niraula S, et al: Toxicity of adjuvant endocrine therapy in postmenopausal breast cancer patients: A systematic review and meta-analysis. J Natl Cancer Inst 103:1299-1309, 2011

23. Giordano SH: Radiotherapy in older women with low-risk breast cancer: Why did practice not change? J Clin Oncol 30:1577-1578, 2012 


\section{Appendix}

\begin{tabular}{|c|c|c|c|c|c|c|}
\hline \multirow{2}{*}{ Characteristic } & \multicolumn{2}{|c|}{ TamRT Arm } & \multicolumn{2}{|c|}{ Tam Arm } & \multicolumn{2}{|c|}{ Total } \\
\hline & No. & $\%$ & $\mathrm{No}$ & $\%$ & $\mathrm{Nh}$ & o \\
\hline Treated patients & 317 & 100 & 319 & 100 & 636 & 100 \\
\hline \multicolumn{7}{|l|}{ Stratification } \\
\hline \multicolumn{7}{|l|}{ ER status } \\
\hline Positive & 313 & 99 & 313 & 98 & 626 & 98 \\
\hline Negative & 4 & 1 & 6 & 2 & 10 & 2 \\
\hline \multicolumn{7}{|l|}{ Tumor size, $\mathrm{cm}$} \\
\hline$\leq 2$ & 310 & 98 & 313 & 98 & 623 & 98 \\
\hline$>2$ & 7 & 2 & 6 & 2 & 13 & 2 \\
\hline \multicolumn{7}{|l|}{ Age at enrollment, years } \\
\hline$<75$ & 141 & 44 & 147 & 46 & 288 & 45 \\
\hline$\geq 75$ & 176 & 56 & 172 & 54 & 348 & 55 \\
\hline \multicolumn{7}{|l|}{ Demographics } \\
\hline \multicolumn{7}{|l|}{ Race } \\
\hline White & 287 & 91 & 287 & 90 & 574 & 90 \\
\hline Hispanic & 5 & 2 & 8 & 3 & 13 & 2 \\
\hline Black & 23 & 7 & 22 & 7 & 45 & 7 \\
\hline Asian & 0 & 0 & 2 & 1 & 2 & $<1$ \\
\hline Other & 1 & $<1$ & 0 & 0 & 1 & $<1$ \\
\hline Unknown & 1 & $<1$ & 0 & 0 & 1 & $<1$ \\
\hline \multicolumn{7}{|l|}{ Diagnostic axillary involvement } \\
\hline Underwent axillary dissection & 122 & 38 & 119 & 37 & 241 & 38 \\
\hline
\end{tabular}

\begin{tabular}{|c|c|c|c|c|c|c|c|}
\hline Study & $\begin{array}{c}\text { No. of } \\
\text { Patients }\end{array}$ & $\begin{array}{l}\text { Follow-Up } \\
\text { (years) }\end{array}$ & Age (years) & $\begin{array}{l}\text { Tumor Size } \\
\text { (cm) }\end{array}$ & Treatment & $\begin{array}{l}\text { Local } \\
\text { Recurrence }\end{array}$ & $\begin{array}{l}\text { Statistical } \\
\text { Significance }\end{array}$ \\
\hline CALGB 9343 & 636 & 10.5 & $\geq 70$ & $\leq 2.0$ & $\begin{array}{l}\text { Tam } \\
\text { TamRT }\end{array}$ & $\begin{array}{l}9 \\
2\end{array}$ & $<.001^{*}$ \\
\hline NSABP B $21^{1}$ & 1,009 & 8 & Any age & $<1$ & $\begin{array}{l}\text { Tam } \\
\text { TamRT } \\
\text { RT placebo }\end{array}$ & $\begin{array}{r}17 \\
3 \\
9\end{array}$ & $<.001$ \\
\hline Winzer et $a l^{5}$ & $361 \dagger$ & 10 & $45-75$ & $\leq 2$ & $\begin{array}{l}\text { Surgery alone } \\
\text { Surgery plus RT } \\
\text { Surgery + tamoxifen } \\
\text { Surgery + RT + tamoxifen }\end{array}$ & $\begin{array}{r}34 \\
10 \\
8 \\
9\end{array}$ & $<.001$ \\
\hline Potter et al ${ }^{4}$ & 869 & 4.5 & Postmenopausal (mean, 66) & $\leq 3$ & $\begin{array}{l}\text { Tam or Al } \\
\text { Tam or Al + RT }\end{array}$ & $\begin{array}{l}6 \\
2\end{array}$ & $<.001$ \\
\hline Fyles et al ${ }^{3}$ & 769 & 5.6 & $>50$ & $\leq 5$ & $\begin{array}{l}\text { Tam } \\
\text { TamRT }\end{array}$ & $\begin{array}{l}8 \\
1\end{array}$ & .001 \\
\hline Tinterri et al ${ }^{10}$ & 749 & 5.0 & $55-75$ & $<2.5$ & $\begin{array}{l}\text { Surgery alone } \\
\text { Surgery + RT }\end{array}$ & $\begin{array}{l}3 \\
1\end{array}$ & .07 \\
\hline Forrest et al‡ & 585 & 6 & $<70$ & $\leq 4$ & $\begin{array}{l}\text { Tam§ } \\
\text { TamRT }\end{array}$ & $\begin{array}{r}25 \\
6\end{array}$ & NS \\
\hline $\begin{array}{l}\text { Abbreviations: } \\
\text { radiation therap } \\
\text { *Locoregional } \\
\text { †347 analyzed } \\
\text { †Forrest et al: } \\
\text { §Or cyclophos }\end{array}$ & $\begin{array}{l}\text { aromatase } \\
\text { am, tamox } \\
\text { urrence. } \\
\text { cet } 348: 70 \\
\text { mide, met }\end{array}$ & $\begin{array}{l}\text { ibitor; CALG } \\
\text { ר alone; Tam } \\
13,1996 \text {. } \\
\text { rexate, and f }\end{array}$ & $\begin{array}{l}\text { Cancer and Leukemia Group } \mathrm{B} \\
\text { tamoxifen plus radiation thera } \\
\text { rouracil based on estrogen rec }\end{array}$ & $\begin{array}{l}\text { S, not stated; } \\
\text { tor status. }\end{array}$ & BP, National Surgical Adjuv & reast and & Project; RT, \\
\hline
\end{tabular}


Lumpectomy Plus Tamoxifen With or Without Irradiation in Older Women With Breast Cancer

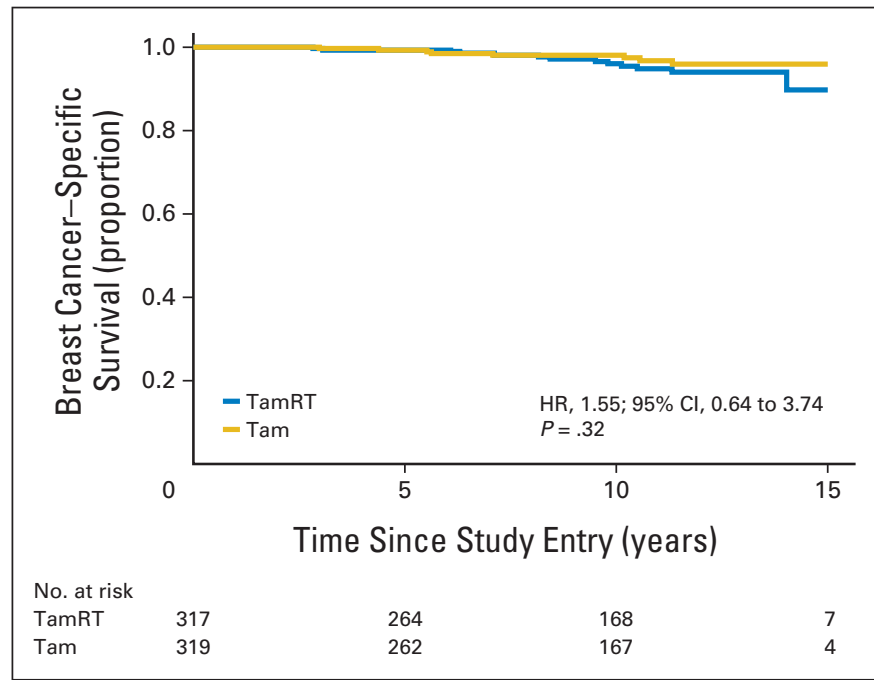

Fig A1. Breast cancer-specific survival. HR, hazard ratio; Tam, tamoxifen alone; TamRT, tamoxifen plus radiation therapy. 